\title{
The Ethical Case against Stem Cell Research
}

\author{
SØREN HOLM
}

\section{Introduction}

The possibility of creating human embryonic stem cell lines from the inner cell mass of blastocysts has led to considerable debate about how these scientific developments should be regulated. Part of this debate has focused on the ethical analysis and part on how this analysis should influence policymaking ${ }^{1}$.

In this paper, I want to look at both issues and present what I believe are the best arguments against the derivation of human stem cells in a way that leads to the destruction or killing of the human entity of which they are a part. My discussion will thus cover:

human embryonic stem cells derived by killing the embryo human fetal stem cells derived by killing the fetus human infant stem cells derived by killing the infant human adult stem cells derived by killing the adult.

The discussion falls in three parts. I first present a critical analysis of the most common arguments showing that the derivation and use of stem cells are morally unproblematic (pro-stem cell arguments). I then look at the arguments showing that the derivation and use of stem cells are problematic (anti-stem cell arguments). Following this, I analyze the policy stalemate that these two opposing views lead to and consider the suggestion that the stalemate can be resolved by requiring consistency between different areas of regulation.

\section{The Reductio of the Pro-Stem Cell Arguments}

By far the most common pro-stem cell argument is that derivation of human embryonic stem cells is morally innocuous because human embryos have no moral status. By analyzing their characteristics, we can see that they are not persons and that it is not wrong to kill them, and we can also see that they do not qualify for any kind of "lower" moral status (for instance, based on sentience). Given that a few other provisos are fulfilled (e.g., concerning permission from the owners of the embryo or gametes), it can then be shown that derivation of stem cells is morally acceptable, perhaps even mandatory. I call this "the standard liberal argument."

One main problem with this argument is that it proves far too much. This is not a new insight, and I do not want to claim any originality for it, but it is 
worth reiterating because the full consequences of the argument are often suppressed in the public debate. The standard argument proves too much in a number of directions.

First, and perhaps most important, it justifies the (nonpainful) killing and use of any prepersonal human entity from the fertilized egg to the prepersonal infant. Such a killing can be justified by any kind of net benefit to others. In the current context, it can therefore just as easily justify the killing of infants for their stem cells as it can the destruction of embryos for the same purpose. There is no in principle difference between the two killings. ${ }^{2}$

Second, it places no restrictions on the use of biological material from prepersonal human entities that can justify the destruction of these entities, as long as those uses are beneficial. The derivation of a new and effective antiwrinkle cream can therefore be a perfectly acceptable justification for the production and destruction of embryos (or fetuses or infants, although the price would probably be quite high for the infant-derived variety). The attraction of the standard liberal argument seems to be twofold: (1) it solves a whole range of bioethical problems in one fell swoop, from embryo research to euthanasia; and (2) it is attractively economical by locating the wrongness of killing in one and only one consideration. One may, however, wonder whether it is not the result of a misapplication of Occam's razor. If moral values and judgments supervene on natural features of the world, do we then have any reason to believe that the supervenience relationship is of the exceedingly simple kind that personhood theories posit? If I tried to claim that the beauty of a painting was only, or even primarily, due to how the color black had been used (i.e., if I claimed that the only part of the painting important to the supervenience relation between the physical painting and our perception of it was the black parts), I would rightly be taken to task for this ludicrous simplification. But are personhood theories not in the same boat by claiming that there is one and only one feature of any killing that makes it wrong?

A further problem is that the standard liberal argument normally hides some real differences between personhood theorists. They may all agree that embryos are not persons, but at the other end of prepersonal human life, in infancy, they advocate slightly different criteria for the ascription of personhood. One set of criteria will therefore permit the killing of a human individual that, based on another set of criteria, would have been strongly prohibited as the killing of a person. Personhood theorists are also wont to claim that personhood is a threshold concept. This threshold claim can be understood in two different ways: first, as a claim that either you are a person or you are not a person and there are no partial persons; and second, as a claim that during the development of an infant personhood is attained at some point and is then a stable trait. The first of these claims does not entail the second nor vice versa. This is important to realize because it could mean that infants go in and out of personhood a number of times during their development. Let us, for instance, say that personhood is dependent on knowing that you have a life (existence over time) and valuing that life (existence over time). ${ }^{3}$ This is clearly a fairly high-level mental trait or ability, and if it develops in a way similar to other high-level traits or abilities, it will not just appear one day and then be present (even as a capability) from then on. Other high-level traits or abilities appear, then disappear, then appear again, and so on until they are finally permanently established. ${ }^{4}$ 
Another type of pro-stem cell argument tries to bypass the question of moral status by showing that stem cell derivation is justified on direct consequentialist grounds. If the good that can be attained is of a sufficient magnitude, then it can outweigh the killing of a certain number of human entities. It is justified to sacrifice some for the benefit of others (as numerous variations of the trolley example are supposed to show ${ }^{5}$ ).

This kind of argument may again prove too much-for instance, that it is also justified to sacrifice some adults if the benefits to others are sufficient.

It does, however, also suffer from another problem caused by the embryonic state of present stem cell research. The benefits that are put into the balance to justify the sacrifice are mainly the therapeutic potential promised by stem cell therapy. The public presentation of the benefits of stem cell research has often been characterized by the promise of huge and immediate benefits. As with many other scientific breakthroughs, the public has been promised real benefits within 5-10 years (i.e., in this case, significant stem cell therapies in routine clinical use). ${ }^{6}$ Several of the 5-10 years have now elapsed, and the promised therapies are still not anywhere close to routine clinical use. ${ }^{7}$ There are similarities to the initial enthusiastic presentation of gene therapy in the late 1980s and the later problems encountered, and some reason to fear that stem cell therapies will have an equally long trajectory between theoretical possibility and clinical practice. It is likely that many of the current sufferers from some of the conditions for which stem cell therapies have been promised will be long dead before the therapies actually arrive. ${ }^{8}$ We are also in a situation where we do not know which, if any, of the possible lines of stem cell research is going to lead to the therapeutic breakthroughs.

This situation can also be modeled by a trolley example. Our trolley is hurtling down the track, and we are approaching a junction where we have to choose between two tracks that both disappear into the distance. On track 1, there are, at what looks like regular intervals, people lying on the track whom we will kill, and there are injured and suffering people sitting at the side of the track whom we will not be able to help. On track 2, the same is the case but there are even more people lying on the track. There is, however, a large sign saying that there is a possibility that we may learn how to stop the trolley somewhere along the track and proceed in a way so that we can both save those lying on the track and help those sitting at the side. Which track should we choose? On track 1 we will be killing and leaving people unhelped, and on track 2 we will be killing more people and leaving the same number unhelped, but we will have the possibility that at some point this will be made good by our learning to stop the trolley and proceeding in a helpful manner. One track has a certain outcome, one an outcome that may be better or may be worse than the baseline certain outcome. Our assessment of what to do must depend on a number of factors, including (1) our assessment of the probability of learning how to stop and of the time span before we have learned this, (2) our assessment of the probability that other things will happen that will remove some people from the track and help the needy at the side, (3) our temporal discount rate, and (4) our degree of risk aversion.

Now, it may be tempting to claim that risk aversivity should play no role in rational decisionmaking, ${ }^{9}$ but, given that the probabilities are not strictly quantifiable, denying a separate role to our attitudes to risk will only mean that 
we will change our (supposedly unbiased) probability estimates to include this attitude component.

In the situation being contemplated here it would be rational to choose track 2, the "uncertain" track, if in our assessment probability 1 was sufficiently high, probability 2 sufficiently low, the predicted time span before stopping low, the temporal discount rate low, and we are risk neutral or not very risk averse. There will thus be a fairly large cluster of estimates of these probabilities that make it rational to choose track 2.

Let us, however, complicate matters by imagining that we are faced with not a two-way choice but a three-way choice. There is yet another track, track 3 , with the same number of people on the track and at the sides as on track 1, the "certain" track. However, on track 3 a large sign says that there is a possibility that we may learn how to stop the trolley somewhere along the track and proceed in a way so that we can both save those lying on the track and help those sitting at the side. It further states that the probability involved may be less than the probability on track 2, but that the information needed to say whether it is less and how much is unavailable at the time we have to choose.

Given that track 3 is no worse and may be better than the first, "certain" track, we know that we should never choose track 1, but the choice between the two uncertain tracks becomes very complicated and will depend critically on our assessment of the different probabilities involved.

Because I am modeling here the current state of stem cell research, we do, however, have a further option. We can send more than one trolley down the tracks. Should we send two trolleys down track 2 and 3? The choice between sending a trolley down track 3 only and sending trolleys down track 2 and 3 will crucially depend on our assessment of whether one of the following scenarios is likely to occur: (1) our progress in finding a way to stop the trolley on track 2 will be so much faster than on track 3, that it outweighs the initial extra loss of life; or (2) on track 2 we will learn things about helping the needy that we will never learn on track 3 . Let us translate this back to stem cell research, where track 2 is destructive research and track 3 all kinds of nondestructive research. If embryos have moral status, our pure consequentialist analysis shows that we should pursue only destructive research (on any kind of human beings) if either (1) this line of research will produce valuable therapeutic results much faster than any of the different nondestructive lines of research, or (2) destructive research will be the only way to produce cures or treatments for certain diseases. At present, I submit that we have no strong reasons to believe that any of these two scenarios are likely to be the case and that the pure consequentialist argument therefore at present supports a restriction of stem cell research to nondestructive research.

\section{The Anti-Stem Cell Arguments}

The direct arguments against the derivation of human embryonic stem cells, the anti-stem cell arguments, do, like the standard liberal argument, focus on the moral status of the embryo.

The standard restrictive argument proceeds from the premise that the life of human individuals is intrinsically valuable at all stages of life. Killing or 
destroying a human being is, therefore, always pro tanto wrong (or, to put it differently, the act always contains at least one wrong-making feature).

The most radical version of the standard restrictive argument claims that all human beings have the same value. On this view, destroying embryos is just as bad as destroying adults, and it seems to rule out any kind of destructive stem cell derivation from embryos (at least if the direct consequentialist argument discussed above does not go through).

This view leads to a number of counterintuitive conclusions in other areas if it is pursued rigorously. It rules out abortion in most, or perhaps all, cases and would, for instance, definitely rule out abortions in cases of rape. It would also put a stop to all kinds of IVF involving the generation of supernumerary embryos and all destructive embryo experiments aimed at improving IVF. It would, finally, also commit us to doing much more to prevent loss of embryos or fetuses during normal reproduction.

Others, including myself, have argued that, although human life is intrinsically valuable at all stages of life, it generally becomes more valuable during the development from fertilized egg to adult human being. This is either argued on the basis of potentiality or on the basis that as the developing human being acquires new characteristics the act of killing it entails more and more wrong-making features (because it deprives it of more and more of what it has, as well as of everything it will get in the future). ${ }^{10}$

It is a commonplace in the "liberal" literature to discount potentiality without any serious consideration, but the arguments used are often exceedingly superficial and build on a conflation of potentiality and mere logical possibility.

On a gradualist analysis of the moral status of the human being through its developmental stages, destroying embryos is always wrong to some degree and cannot be done just for any kind of benefit. One great advantage of a gradualist analysis applied to stem cell research is that it can explain why destructive use of embryos for stem cell production is less problematic than the destructive use of fetuses, or infants.

But if embryos have value, the question is whether the benefits of stem cell research are of the right kind and large enough to justify the destruction of some valuable embryos. The benefits definitely seem to be of the right kind. Helping or perhaps even curing people who are suffering from horrendous diseases is clearly an ethically worthwhile activity and a good goal to pursue. ${ }^{11}$ But what about the magnitude of the benefit; is it also large enough?

One way of answering this question is by finding some other analogous activity where we sacrifice embryos to produce some good. It has been argued by my colleague John Harris that "normal" reproduction is such an activity. ${ }^{12}$ For every pregnancy brought to term, on average 3-5 embryos fail to implant or undergo spontaneous abortion some time during pregnancy. Harris argues that, if we accept that loss of embryos by engaging in reproduction (or just not protecting against reproduction), we are forced by reasons of consistency also to allow similar sacrifice of embryos for goals of equal importance. Let us for the sake of argument accept Harris's analysis. ${ }^{13}$ How much embryonic stem cell research would it commit us to allowing?

If the trade-off is one life produced for every six embryos used, probably not very much. First, we have to remember that we cannot just count lives saved by stem cell therapies and assume that if we save one life for every six embryos destroyed we will be ethically all right. We can save the same life many times, 
and it is questionable whether every new saving counts equally. If I am hand-ventilating a patient, do I save his life anew with every compression of the ventilation bag? ${ }^{14}$ We also have to take account of the fact that many stem cell therapies are not lifesaving but life extending or quality-of-life enhancing. We therefore need a metric that can take account of all of these considerations. One such metric is the QALY (quality adjusted life year). QALYs have many problems, but none of them should be of relevance to the following analysis.

Assuming a low-average life span of 72 years for a newborn, the "normal" trade-off works out as 12 life years per embryo, or, if we assume that some of these are of lower quality than others so that the net QALY gain per newborn is only 60 QALYs, we still have a trade-off of 10 QALYs per embryo.

A recent paper from one of the well-known groups in the field reports the generation of one definite and two possible embryonic stem cell lines from 50 blastocysts (and 101 fertilized eggs). ${ }^{15}$ If we assume that all the cell lines are true embryonic stem cells, this is equivalent to a 1 in 16.6 ratio between embryo use and cell line production.

If all three cell lines turned out to be therapeutically useful, it would thus seem that they would each have to produce health improvements equivalent to at least 166 QALYs to be equivalent to normal human reproduction. ${ }^{16}$ It is, however, unlikely that all the cell lines generated will ever have any therapeutic usefulness. Many will only be used for basic research, and others will be discarded because they are less easy to work with than other similar lines. It might also be the case that the use of adult stem cell lines derived in nondestructive ways will become the preferred option in a number of therapeutic areas, or we may be able to create stem cells without the involvement of embryos, both developments leaving the derived embryonic stem cell lines unproductive. We are still at such an early stage of development that we have no way of estimating how many of the stem cell lines that are derived will eventually be used for therapeutic purposes. But, all in all, the considerations here indicate that on this type of consistency argument the stem cell lines that are actually used would have to produce major therapeutic benefits.

As discussed in the first section of this paper, the standard liberal argument has a number of rather embarrassing consequences if it is really taken seriously. The same is true of the standard restrictive argument discussed in this section, even in its gradualist version. If embryos have significant moral status it would commit us to a much stricter abortion policy than many find acceptable, although it would be possible to allow abortions in certain circumstances, and it would also commit us to rethinking our research priorities with regard to embryo and fetal loss during normal pregnancy.

\section{The Policy Stalemate}

As I have discussed, each side in the debate on stem cells has a number of rather nasty skeletons in their ethical cupboard that are usually hidden from public view. The full implications of the views are not explored in public debate, and if they are pointed out by opponents they are often dismissed as irrelevant to the current debate. This unfortunately leads to a dishonest public debate. The participants are perhaps on analysis minimally truthful (i.e., they do not lie), but they nevertheless argue in a way that is (intentionally?) misleading. 
These features of the debate contribute to the policy stalemate that can be discerned in every country where public policy has been formulated on human embryonic stem cells. Neither side of the debate has a policy that is consistent with the full implications of its arguments, ${ }^{17}$ and neither side seems very interested in pressing for such a fully consistent policy!

This situation should perhaps in itself make us wary of trying to decide public policy based purely on consistency arguments (because they seem to be very selectively employed), but let us nevertheless as good philosophers try to see how far consistency will get us when applied to the regulation of stem cell research.

When consistency is invoked concerning public policy, the claim is that certain features of current regulation in a specific area logically (or perhaps slightly weaker, morally) commit regulators to regulate new areas in a specific way for reasons of consistency or parity of reasoning. ${ }^{18}$ This type of argument occurs in two subtypes. The first subtype is:

1. Authority $\mathrm{X}$ promulgates regulation $\mathrm{R}$.

2. X puts forward an incomplete argument A supporting $\mathrm{R}$.

3. A can be made complete by the addition of premises $P_{1}-P_{n}$.

4. The complete argument A will (perhaps with the addition of some further premises that $X$ accepts) also support regulation $C$.

5. $\mathrm{X}$ is therefore, by parity of reasoning, committed to accept regulation $\mathrm{C}$.

The second subtype is:

1. Authority X promulgates regulation $\mathrm{R}$.

2. The justification for $R$ can be reconstructed as argument $A^{*}$.

3. The argument $A^{*}$ will (perhaps with the addition of some further premises that $X$ accepts) also support regulation $C$.

4. $\mathrm{X}$ is therefore, by parity of reasoning, committed to accept regulation $\mathrm{C}$.

These "official policy" based arguments may fail if our reconstruction and completion of the underlying arguments are wrong, but a further possible mode of failure occurs if the regulation $\mathrm{R}$ has been promulgated in a situation where $R$ is the result of a compromise, either because $X$ has openly engaged in a compromise with some other group or because $X$ has already taken the views of some other group into account when drafting the regulation (for instance, to ensure a smooth passage through the political process). If a regulation is based on a political compromise, it may well be the case that no one wants to defend or justify the position reached in the regulation, except as a legitimate result of a legitimate political process. ${ }^{19}$

An example could be the abortion legislation in countries allowing abortion on demand until a certain gestational age. It is unlikely that many people would actually claim to have an argument that can justify the exact limit legislated in a specific country, but many more might be willing to accept it as a legitimate political compromise between those wanting a higher limit and those wanting a lower limit. Such laws do, therefore, not necessarily imply that something radical is thought to happen to the moral status of the fetus or the moral rights of the mother when the gestational age in question is reached.

A consistency argument based on official policy also needs to take into account that there are limits to the preciseness with which one can draft 
regulation and that ethically extraneous factors play a role. As Beauchamp and Childress write:

\begin{abstract}
Public policy is often formulated in contexts that are marked by profound social disagreements, uncertaincies, and different interpretations of history. No body of abstract moral principles and rules can determine policy in such circumstances, because it cannot contain enough specific information or provide direct and discerning guidance. The specification and implementation of moral principles and rules must take account of problems of feasibility, efficiency, cultural pluralism, political procedures, uncertainty about risk, noncompliance by patients, and the like. (pp. 8-9) ${ }^{20}$
\end{abstract}

In evaluating official policy it is also very important not to forget that the ideal policy has to be both locally and globally coherent and consistent and that maximal coherence in a body of regulations may be achieved by allowing some local inconsistencies. In many legal systems it is, for instance, accepted that a major change in legal status occurs at birth. This principle permeates many areas of law, also outside of the laws strictly dealing with reproductive matters, and it is at least arguable that global consistency is better served by upholding it in all cases, even if there are a few cases where it might seem to be locally inconsistent.

In the context of stem cell research, one particular consistency argument is often put forward claiming that, because destructive research using embryos for certain purposes is already allowed in a given jurisdiction, consistency requires that we allow the destructive use of embryos for stem cell research. ${ }^{21,22}$

Many countries that presently allow experiments on embryos restrict these experiments to those related to improving reproductive technologies and increasing our understanding of the biology of human reproduction. Many types of stem cell research fall outside this restriction and are therefore not permitted even though the jurisdictions in question allow other forms of research on embryos.

Can a restriction of embryo research to reproductive matters be justified?

The decision to allow embryo research for a restricted range of research questions could possibly be reconstructed as an attempt to achieve consistency in a situation where embryo research is believed to be (somewhat) ethically problematic. ${ }^{23}$ Most legal regulation of embryo research occurs within the broader context of regulation of assisted reproductive technologies, and it is evident that these technologies could only have been developed, and can only be improved, if embryo research is permitted. Any legislation that allows the use of assisted reproductive technologies and prohibits embryo research could therefore be charged with a form of performative inconsistency, by prohibiting a necessary step in the development and improvement of a permitted technique. ${ }^{24}$

Would it then be inconsistent not to allow research using embryos with no connection to reproduction?

Michael Walzer has famously argued that society contains several separate "spheres of justice" and that the application of principles of justice from one sphere to another is not necessarily warranted..$^{25}$ Maybe there are also separate "spheres of consistency" when we discuss the consistency of public regulations. This is not as strange an idea as it might perhaps initially seem. 
Walzer's argument for different spheres of justice is that different social goods are different and that, unless we understand and take account of this difference in our analysis of justice, we will go wrong. He writes:

No account of the meaning of a social good, or of the sphere within which it legitimately operates, will be uncontroversial. Nor is there any neat procedure for generating or testing different accounts. At best, the arguments will be rough, reflecting the diverse and conflictridden character of the social life that we seek simultaneously to understand and to regulate-but not to regulate until we understand. I shall set aside, then, all claims made on behalf of any single distributive criterion, for no such criterion can possibly match the diversity of social goods. ${ }^{26}$

In the same way as different social goods are different, the different social practices aimed at producing these social goods are different. The practices involved in reproduction and in securing the goods secured by reproduction are different from the practices involved in research. There is thus no prima facie reason to believe that arguments and conclusions valid in one of these areas can be transferred without modification to the other area. Let me try to illustrate this.

In the area of reproductive ethics the idea that there is a strong right to reproductive freedom or reproductive liberty has gained currency in recent years. If a given permissive legal regulation has been passed because of an appreciation of this right (for instance, concerning the creation, use, and destruction of embryos in the sphere of ARTs), then it is not immediately obvious that consistency requires the same kind of permissive regulation outside of the sphere of reproduction. A right to reproductive liberty cannot, for instance, in itself support a permission to use embryos for nonreproductionrelated purposes, such as stem cell research! And, given that the right to reproductive liberty is most often justified by arguments pointing to the central position of reproductive projects in the lives of (most) people, it also follows that the consideration justifying a right to reproductive liberty cannot directly support the production of embryos for nonreproduction-related purposes (whether they be research or other purposes).

In looking at consistency arguments in the public policy sphere, we might also want to question whether "as morally acceptable" 27 is a transitive relation in this context. If $\mathrm{p}$ is as morally acceptable as $\mathrm{q}$, and $\mathrm{q}$ is as morally acceptable as $r$, have we therefore committed ourselves to the judgment that $p$ is as morally acceptable as $\mathrm{r}$ ?

Moral acceptability comes in at least two different forms, and the difference between them can be brought out by considering Tranøy's analysis of moral disagreement and consensus. If two people A and B discuss the morality of $\mathrm{p}$, there are, according to Tranøy, three possible outcomes:

1. Person A and B can agree that $\mathrm{p}$ is unacceptable, i.e., both mean positively that $\mathrm{p}$ should not be accepted,

2. A and B can agree that $\mathrm{p}$ is acceptable, i.e., both mean positively that $\mathrm{p}$ should be accepted,

3. A and B can agree that $\mathrm{p}$ is acceptable, but A or B might abstain from actively taking a stand on p. (p. 155) $)^{28}$

Tranøy calls the last option "open consensus." 29 
Let us call the kind of moral acceptability where both decisionmakers positively affirm the moral acceptability of $\mathrm{p}$ "moral acceptability" and the kind of moral acceptability where one of the decisionmakers abstains from taking a stand on $\mathrm{p}$ "moral acceptability*." Let us assume that moral acceptability is transitive; does this entail that moral acceptability* is also transitive? Clearly not. The judgment of moral acceptability* may occur for a number of different reasons. The case $\mathrm{p}$ may for $\mathrm{B}$ be in a gray area between the clearly acceptable or the clearly unacceptable, or B may defer to A's judgment because the question at issue is much more important for A. Moral acceptability* is thus only transitive in those cases where B's reason for abstaining from actively taking a stand on $\mathrm{p}$ is shared by $\mathrm{q}$ and $\mathrm{r}$, and, because these reasons may be nonmoral, transitivity of moral acceptability* only occurs if we can claim parity of reasoning for both the moral features and the nonmoral features of $p, q$, and $\mathrm{r}$.

It should be relatively obvious that the kind of moral acceptability that lies behind public regulation of controversial areas in bioethics is most often not moral acceptability but moral acceptability*. This means that purely ethical consistency arguments are often misapplied, because they assume a transitivity of moral acceptability that often is not there.

\section{Conclusion}

In this paper, I established that the standard liberal arguments for allowing stem cell research are problematic, as are the standard restrictive arguments. For this reason, they cannot be used to guide public policy.

I have further shown that any line of argument trying to circumvent a reliance on the standard arguments by instead relying on consistency to guide public policy formation in this area is also problematic because (1) there are general problems with consistency arguments as they are currently used, (2) there are specific problems affecting consistency arguments in public policy, and (3) there are even more specific problems in seeking consistency between the sphere of reproductive issues (where personal reproductive liberty plays a major role) and the sphere of research and therapy.

These conclusions are all negative but should not, on reflection, be terribly controversial. ${ }^{30}$ The positive, but controversial, conclusion is that at least some of these problems can be resolved by adopting a gradualist position on the moral status of the embryo. If we adopt a gradualist position, we will find that we need good reasons to perform any kind of experiments on embryos but that such experiments are not ruled out tout court. This means that it is up to the scientists to present convincing arguments that destructive embryonic stem cell research is necessary to produce cures and treatments for important human diseases.

\section{Notes}

1. For a review of the debate, see: Holm S. Going to the roots of the stem cell controversy. Bioethics 2002;16:493-507.

2. We might try to say that, if we want to kill the prepersonal infant for its stem cells, we need the permission of its parents and that the parents are then obliged to take the best interests of the 


\section{Søren Holm}

infant into account (and presumably not allow the killing). This may be correct in law, because the law considers every born human being as a person, but it is not morally justifiable on the standard argument. If the infant is not a person, the parents are not proxy decisionmakers but simply decisionmakers for a piece of property in which they have invested time and resources.

3. This is close to the Harris and Tooley positions.

4. Lee V, Gupta PD, eds. Children's Cognitive and Language Development. Oxford: Blackwell; 1995. McShane J. Cognitive Development: An Information Processing Approach. Oxford: Blackwell; 1991. Piaget J, Inhelder B. The Growth of Logical Thinking from Childhood to Adolescence. New York: Basic Books; 1958.

5. Kamm FM. The doctrine of triple effect and why a rational agent need not intend the means to his end. Proceedings of the Aristotelian Society 2000;S74:21-39; Harris J. The moral difference between throwing a trolley at a person and throwing a person at a trolley. Proceedings of the Aristotelian Society 2000;S74:40-57.

6. Anonymous. Taking stock of spin science. Nature Biotechnology 1998;16:1291.

7. Given the time needed for basic research, clinical research, and regulatory approval, it is unlikely that any therapy using biological materials and based on a truly novel therapeutic approach could move from initial discovery to clinical use in 5-10 years. See also: Lovell-Badge R. The future for stem cell research. Nature 2001;14:88-91.

8. Albert B. Presentation to the All-Party Disablement Group. Unpublished manuscript; 2000 Jul 25.

9. This is, for instance, a central point in the argument between John Rawls and his consequentialist critics about his argument that a rational decisionmaker behind the veil of ignorance would choose the maximin decision to the distribution of basic goods.

10. Holm S. The moral status of the pre-personal human being: the argument from potential reconsidered. In: Evans D, ed. Conceiving the Embryo. Dordrecht: Kluwer; 1996:193-220.

11. Whether the same can be said about basic biological research using human embryonic stem cells is another matter.

12. Harris J. The ethical use of human embryonic stem cells in research and therapy. In: Burley J, Harris J, eds. A Companion to Bioethics. Oxford: Blackwell; 2002:158-74.

13. Most gradualists would probably argue that embryos have more value than one-sixth of an adult life and that the reason we "allow" loss of embryos in reproduction is not primarily connected to the value of the embryos.

14. This issue is quite complex, and intuitions may vary from case to case. Here is one more case supporting the line I take on repeated savings. Let us imagine that by killing one person and removing his organs we can get five organs that are life saving for others. This might, on a utilitarian analysis, justify the killing as shown by John Harris in his famous survival lottery paper. But would it also justify killing the one person in a situation where we knew that a person would need the five organs sequentially over a period of 25 years - that is, where we had five lifesaving episodes, but all of these were lifesaving for the same person? In my book, this would be to kill one person to save the life of one other person-not killing one to save five.

15. Lanzendorf SE, Boyd CA, Wright DL, Muasher S, Oehninger S, Hodgen GD. Use of human gametes obtained from anonymous donors for the production of human embryonic stem cell lines. Fertility and Sterility 2001;76(1):132-7.

16. This, by the way, indicates that it is quite unlikely that this consistency argument could ever show individually targeted stem cell production (for instance, by nuclear replacement) to be ethically acceptable. Unless longevity increases enormously it will simply be close to impossible to generate the requisite number of QALYs or unadjusted life years. This will be the case even if you could use the same cell line for a number of different therapies in the same person. It will still be very difficult to cram 166 QALYs into one life.

17. It is important to note that this is true both in restrictive and liberal jurisdictions. The restrictive regulations of the United States are not nearly restrictive enough and the liberal regulations of the United Kingdom not nearly liberal enough to match the philosophical arguments.

18. The following section is a slightly amended section from my paper Parity of reasoning arguments in bioethics-some methodological considerations. In Häyry M, Takala T, eds. Scratching the Surface of Bioethics. Amsterday: Rodopi; 203:45-56.

19. It is usually accepted that a political decision can be legitimate even in cases where it can be argued not to be optimal.

20. Beauchamp TL, Childress JF. Principles of Biomedical Ethics, 5th ed. New York: Oxford University Press; 2001. 


\section{The Ethical Case against Stem Cell Research}

21. Harris J. The ethical use of human embryonic stem cells in research and therapy. In: Burley J, Harris J, eds. A Companion to Genethics. Oxford: Blackwell; 2002:158-74.

22. The possible policy responses to stem cell research also raise a number of other consistency issues that will not be discussed in detail here. These include questions of consistency with regard to (1) legal permission of certain kinds of stem cell research and prohibition of public funding of the same kinds of research, and (2) legal prohibition of derivation of stem cell lines from embryos and permission to import and use cell lines derived elsewhere.

23. Many public policies seem to indicate that people are "closet gradualists" with regard to the moral status of embryos and fetuses.

24. It is unclear whether any formal inconsistency would be implied. It is still an open question whether subsequent use of research data obtained in unethical experiments (e.g., the Nazi concentration camp experiments) is in itself ethically problematic.

25. Walzer M. Spheres of Justice: A Defence of Pluralism and Equality. Oxford: Blackwell; 1983.

26. See note 25, Walzer 1983:21.

27. Or the many similar locutions like "as ethically justified."

28. Tranøy KE. Det Åpne Sinn: Moral og Etikk mot et Nytt Årtusen [The Open Mind: Moral and Ethics in a New Millennium]. Oslo: Universitetsforlaget; 1998. I owe the translation from Norwegian to Jan Helge Solbakk.

29. Open consensus can also occur around the judgment that $\mathrm{p}$ is unacceptable if either A or B abstains from actively taking a stand on $p$.

30. Even the most insistent liberal and conservative philosophers usually shy back if asked whether they want to implement the full implications of their position as social policy. 